\title{
High-Altitude Pulmonary Edema in Ohio at an Elevation of 339 Meters
}

This article was published in the following Dove Press journal:

Open Access Emergency Medicine

\section{Christina Walker (D) \\ Benjamin Miner \\ Todd Bolotin}

Department of Emergency Medicine, Mercy Health St. Elizabeth Boardman Hospital, Youngstown, OH, USA
Correspondence: Christina Walker

Tel + I 502-295-9859

Email cbwalker II@gmail.com
Background: HAPE (High-Altitude Pulmonary Edema) is a life-threatening form of high-altitude illness caused by noncardiogenic pulmonary edema. It has been most commonly reported in individuals who live at lower elevations and travel to elevations above $2500 \mathrm{~m}$, typically in those who do so without any acclimatization. It can also occur in residents of high altitudes who descend to lower altitudes and then return to their native altitude without acclimatization. HAPE is more common in individuals with a history of prior HAPE, very rapid rates of ascent, upper respiratory illness, extreme exertion and cold environmental temperatures, Down's Syndrome, obesity and congenital pulmonary anomalies.

Case Presentation: Our case discusses a patient presenting to an emergency department in Ohio with severe respiratory distress, hypoxia and a radiograph that showed pulmonary edema without cardiomegaly. Additional history revealed the patient had recently returned from Breckenridge, Colorado (an elevation of approximately $2926 \mathrm{~m}$ ). The diagnosis of HAPE was recognized and he was appropriately treated. He was educated and will not be returning to high altitude without acclimatization in the future.

Conclusion: Upon literature review, there has never been a prior documented case of a patient in Ohio with HAPE. Providers must consider altitude illness when evaluating travelers from high altitude destinations, even when traveling to a very low altitude like Ohio, as symptoms may be unresolved by descent alone. This case emphasizes the importance of obtaining relevant historical data including a travel history. It also emphasizes the importance of avoiding early closure of the diagnostic process by only considering common conditions. Finally, the case emphasizes the potential danger of anchoring bias to previously encountered conditions.

Keywords: high-altitude pulmonary edema, environmental emergencies

\section{Background}

There are many common etiologies of dyspnea for a patient who presents to an emergency department in Ohio. ${ }^{3}$ HAPE is essentially never considered in the differential diagnosis at our altitude of $339 \mathrm{~m}$. The diagnosis of pulmonary edema secondary to high altitude in a low altitude environment requires a high index of suspicion and a focused travel history. Providers should caution patients about returning to high altitude due to the increased chance of recurrent HAPE. The Lake Louise scoring system is used to identify patients with HAPE and other forms of altitude illness. ${ }^{4}$ Oxygen supplementation and descent are the main therapies for HAPE, although calcium channel blockers, phosphodiesterase inhibitors, and steroids have been used. ${ }^{5}$ 


\section{$\mathbf{R}$}

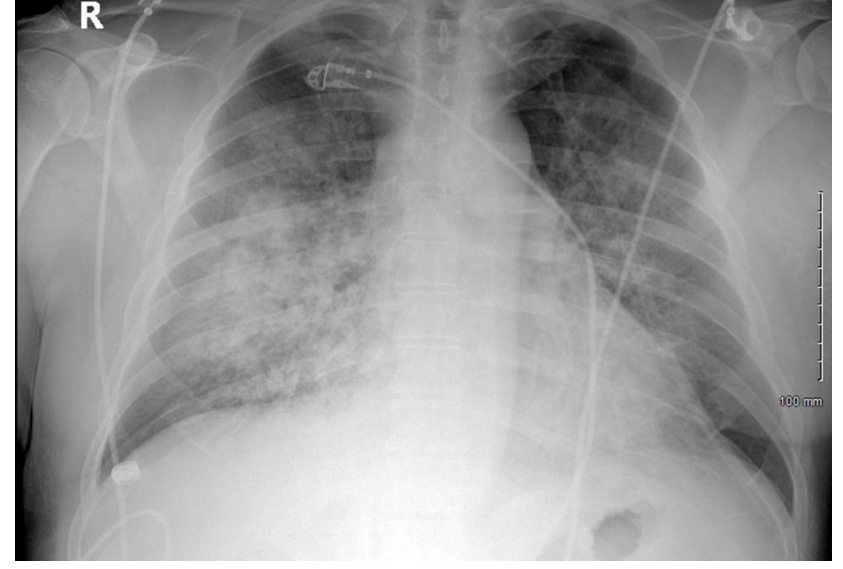

Figure I Emergency department chest X-ray showing pulmonary edema without cardiomegaly.

\section{Case Presentation}

The patient was a 58-year-old non-smoking male Ohio native with hyperlipidemia, environmental allergies and no other known medical problems who presented to the emergency department within hours of his return from a ski trip to Breckenridge, Colorado (altitude $2926 \mathrm{~m}$ ) complaining of dyspnea, orthopnea, dizziness, chest tightness and weakness in the pre-Covid-19 era. He developed mild dyspnea within 48 hours of arrival to Colorado but returned to Ohio after five days with increasing dyspnea that did not improve with descent. His initial evaluation revealed a pale mildly diaphoretic adult in severe respiratory distress who was able to speak in short sentences. His initial vital signs were blood pressure 189/ $101 \mathrm{mmHG}$, temperature $37^{\circ} \mathrm{C}$, respirations of 40 breaths per minute, and pulse rate of 112 beats per minute. Physical exam was significant for normal cardiac exam except tachycardia, increased work of breathing, conversational dyspnea, bibasilar rales, normal heart sounds, $2+$ distal pulses without peripheral edema and mildly diaphoretic cool skin. Oxygen saturation on room air was $72 \%$ and chest X-ray demonstrated pulmonary edema without cardiomegaly (Figure 1). Electrocardiogram revealed sinus tachycardia of 104 beats per minute with minimal flattening of the T-waves in V5 and V6. Lab work revealed an elevated white blood cell count of 21.6 Reference Interval (RI) (4.5-11.5E9/L), a normal hemoglobin of $13.7 \mathrm{RI}(12.5-16.5 \mathrm{~g} / \mathrm{dl})$ and an elevated brain natriuretic peptide level of $1031 \mathrm{RI}(0-125 \mathrm{pg} / \mathrm{dl})$, three serial troponin levels were less than $0.01 \mathrm{RI}(0.00-0.03 \mathrm{ng} / \mathrm{mL})$. D-dimer level was not obtained due to the pulmonary infiltrates and a basic metabolic panel was normal, as was a viral respiratory film array panel, and two sets of blood cultures.
A trans-thoracic echocardiogram revealed normal valvular function and an ejection fraction of $65 \%$ with normal diastolic function. The echocardiogram did not include a pulmonary ultrasound and B-lines were not assessed. Pulmonary consultation noted rapid resolution of the pulmonary infiltrates as well as hypoxia with the emergency department treatment and a decision not to perform bronchoscopy was made. In the emergency department, nitroglycerine $0.4 \mathrm{mg}$ sublingually, extended-release nifedipine $30 \mathrm{mg}$ orally, and dexamethasone $10 \mathrm{mg}$ intravenously were administered. A brief emergency department literature review led to this therapeutic regimen. Due to persistent dyspnea despite resolving hypoxia, he was placed on bilevel positive airway pressure (BIPAP) at 15/5 $\mathrm{cmH} 2 \mathrm{O}$ with further improvement in his dyspnea. Due to the local lack of familiarity with HAPE, he was admitted to the intensive care unit where the BIPAP was continued until he could be weaned to room air and was subsequently discharged on no medications. He was counseled against further trips to high altitude without acclimatization.

\section{Discussion and Conclusions}

HAPE is a life-threatening form of high-altitude illness caused by noncardiogenic pulmonary edema. ${ }^{1}$ HAPE has been reported to occur at elevations above $2500 \mathrm{~m}$, especially without prior acclimatization. Pulmonary edema occurs due to increased pulmonary artery pressures caused by hypoxic pulmonary vasoconstriction and increased capillary leakage due to hypoxia. ${ }^{2}$ The Lake Louise score was created at the 1991 International Hypoxia Symposium and is still used to identify patients with high altitude illness. In the setting of the recent gain in altitude, the presence of at least 2 symptoms and 2 signs identifies HAPE. Symptoms include dyspnea at rest, cough, weakness or decreased exercise performance, chest tightness or congestion. Signs include crackles or wheezing in at least one lung field, central cyanosis, tachypnea, or tachycardia. ${ }^{4}$ Calcium channel blockers have been used in the treatment of HAPE. Dexamethasone is useful for prophylaxis in patients with acute mountain sickness and HAPE. ${ }^{5}$ Oxygen supplementation and descent are the main treatment for HAPE because they both help to reverse the pathophysiology by decreasing the hypoxic pulmonary artery vasoconstriction. ${ }^{2}$ Supplemental intravenous fluids are not contraindicated because in contrast to cardiogenic pulmonary edema left ventricular ejection fraction is preserved in these patients, and volume overload and passive pulmonary congestion due to elevated hydrostatic pulmonary artery pressure is not the primary pathophysiology. ${ }^{2}$ 
Acclimatization and pretreatment with acetazolamide or phosphodiesterase inhibitors should also be discussed with those traveling to high altitude, although acetazolamide therapy is contraindicated for HAPE treatment due to concerns for increased acidosis and intravascular volume contraction. ${ }^{5}$ High altitude pulmonary edema is primarily due to rapid elevation gains above 2500 meters without proper acclimatization in susceptible individuals. Our case demonstrates a healthy male who had vacationed in Colorado and returned to Ohio with respiratory complaints and severe hypoxia. He was treated for HAPE by physicians unfamiliar with altitude illness and improved. He was educated on travel to altitude and encouraged in the future to seek ski destinations with lower elevations or to properly acclimatize before ascent given his predisposition to this potentially fatal condition.

\section{Abbreviations}

HAPE, High-Altitude Pulmonary Edema; BiPAP, Bilevel Positive Airway Pressure; RI, Reference Interval.

\section{Data Sharing Statement}

All data generated or analyzed during this study are included in this published article.

\section{Ethics Approval and Consent to Participate}

This case report was submitted to the IRB for approval for publication. Per institutional policy, this case report is exempt from IRB review. The patient's signed written informed consent has met our institutional policy on case report publication. The patient has executed a signed written informed consent allowing the publication of the case details, figures and accompanying images. The authors also attest that no further data will be shared beyond that already present in the manuscript.

\section{Consent for Publication}

Written informed consent was obtained from the patient for publication of this case report and any accompanying images. A copy of the written consent is available for review by the Editor-in-Chief of this journal.

\section{Author Contributions}

All authors made substantial contributions to conception and design, acquisition of data, or analysis and interpretation of data; took part in drafting the article or revising it critically for important intellectual content; agreed to submit to the current journal; gave final approval of the version to be published; and agree to be accountable for all aspects of the work.

\section{Disclosure}

The authors declare they have no competing interests.

\section{References}

1. DeVos E, Jacobson L. Approach to adult patients with acute dyspnea. Emerg Med Clin North Am. 2016;34(1):129-149. doi:10.1016/j. emc.2015.08.008

2. Sutton JR, Coates G, Houston CS The Lake Louise consensus on the definition and quantification of altitude illness. In: Hypoxia and mountain medicine: proceedings of the 7. International Hypoxia Symposium, held at Lake Louise, Canada, February 1991. Oxford, VT: Pergamon Press; 1992.

3. Luks AM, Auerbach PS, Freer L, et al. Wilderness medical society clinical practice guidelines for the prevention and treatment of acute altitude illness: 2019 update. Wilderness Environ Med. 2019;30(4S): S3-S18. doi:10.1016/j.wem.2019.04.006

4. Singh I, Kapila CC, Khanna PK, Nanda RB, Rao BD. High-altitude pulmonary edema. Lancet. 1965;285:229-234. doi:10.1016/S01406736(65)91520-5

5. Grissom CK, Elstad MR. The pathophysiology of high altitude pulmonary edema. Wilderness Environ Med. 1999;10(2):88-92. doi:10.1580/1080-6032(1999)010[0088:TPOHAP]2.3.CO;2
The Open Access Emergency Medicine is an international, peerreviewed, open access journal publishing original research, reports, editorials, reviews and commentaries on all aspects of emergency medicine. The manuscript management system is completely online and includes a very quick and fair peer-review system, which is all easy to use. Visit http://www.dovepress.com/testimonials.php to read real quotes from published authors. 